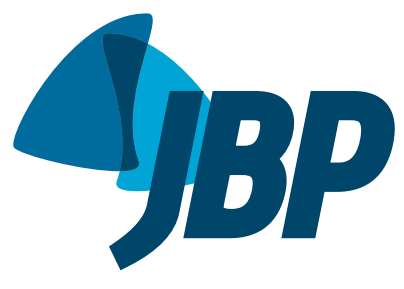

\title{
Influence of a heat and moisture exchanger with a microbiological filter on measurements of maximal respiratory pressures and vital capacity in patients with COPD
}

\author{
Jeanette Janaina Jaber Lucato, ${ }^{1, a}$, Renata Cléia Claudino Barbosa1,b, \\ Patricia Salerno de Almeida Picanço ${ }^{1, c}$, Thiago Marraccini Nogueira da Cunha ${ }^{2, d}$, \\ Renato Fraga Righetti3,e
}

\section{TO THE EDITOR:}

COPD is characterized by persistent respiratory symptoms such as dyspnea, which contributes to decreased exercise tolerance. One of the main mechanisms involved is respiratory muscle dysfunction. ${ }^{(1)}$ Therefore, changes in lung volumes and capacities, especially reduced VC, can be observed in patients with COPD, as can respiratory muscle weakness. ${ }^{(2)}$

The measurement of $\mathrm{VC}$ and respiratory pressures (MIP and MEP) is performed using a spirometer (Figure $1 \mathrm{~A})$ and a manometer (Figure $1 \mathrm{C}$ ), respectively. These devices are cleaned only externally, which may contribute to the increased incidence of infections, given that no device is utilized to filter the air inhaled and exhaled by patients during routine evaluations. ${ }^{(3)}$ Therefore, a viable alternative would be to use heat and moisture exchangers (HMEs) on such equipment.

A hydrophobic HME contains an inline, disposable, hygroscopic, bacteriostatic sponge (microbiological filter, Figures $1 \mathrm{~B}$ and $1 \mathrm{D}$ ) that reduces device contamination, thus protecting patients from microbial contamination. ${ }^{(4)}$

Lucato et al. ${ }^{(5)}$ demonstrated that the dead space volume and resistance caused by the addition of an HME did not change the VC or respiratory muscle strength values in volunteers evaluated during spontaneous breathing. To our knowledge, there have been no studies aimed at determining whether the addition of a microbiological filter has a relevant impact on those variables in patients with impaired pulmonary function. However, such studies are important because it has been reported that the use of an HME may lead to increased pulmonary resistance, ${ }^{(6)}$ which can cause problems in patients with COPD.

The objective of the present study was to determine whether the use of an HME with a microbiological filter alters maximal respiratory pressures or VC in patients with COPD.

We conducted a cross-sectional study in which the start sequence of the evaluation (presence or absence of an HME) was randomized, including 16 patients with COPD undergoing treatment in the cardiopulmonary and metabolic rehabilitation sector of a teaching clinic. The mean $\mathrm{FEV}_{1}$ in those patients was $36.01 \pm 10.56 \%$ of the predicted value and the mean $\mathrm{FEV}_{1} / \mathrm{FVC}$ ratio was 54.29 $\pm 10.01 \%$ of the predicted value. The sample size was determined by convenience sampling, which explains the small number of patients and may be a limitation of the study. This study was approved by the Research Ethics Committee of the Centro Universitário São Camilo (Ruling no. 2,075,696), and all participating patients gave written informed consent. The inclusion criteria were having a spirometry-confirmed diagnosis of COPD and having had no exacerbations in the last six months. Patients who had recently undergone thoracic or abdominal surgery were excluded, as were those presenting with facial deformities, cognitive impairment, myopathy, or acute middle ear infection.

The VC, MIP, and MEP were evaluated with and without an HME (Lumiar Bacteriological Filter; Besmed Health Business Corp., New Taipei City, Taiwan), which is indicated for filtering material from room air and gases, thereby reducing the risk of cross contamination. The filter membrane has high (> 99.99\%) bacterial filtration efficiency. The HME was positioned between the mouthpiece and the ventilation equipment. For each variable studied, three measurements were obtained. The highest value was considered for the analysis and then compared with the value obtained without the use of an HME in the same patient. We employed a Ferraris Mark 8 spirometer (Ferraris Respiratory Europe, Hertford, UK) and a Ger-Ar manometer (Ger-Ar-SP Com. Equip. Ltda., São Paulo, Brazil).

The numerical data are expressed as mean and standard deviation and tested for normality using the Shapiro-Wilk test. For comparisons between the two groups-without an HME (conventional method) and with an $\mathrm{HME}$-in terms of the evaluations of VC, MIP, and MEP, we used paired t-tests. The SigmaStat program, version 11.0 (Systat Software, Inc., San Jose, CA, USA) was used, and the level of statistical significance was set at $p<0.05$.

We selected 16 patients diagnosed with COPD, of which 11 were male. The mean age, weight, and height were $69.9 \pm 7.7$ years, $66.0 \pm 15.3 \mathrm{~kg}$, and $1.62 \pm 0.11 \mathrm{~m}$, respectively, and the mean body mass index was 24.84 $\pm 5.04 \mathrm{~kg} / \mathrm{m}^{2}$.

There were no significant differences between the conventional method and the method that involves the use of an HME in terms of the MIP $\left(-66.5 \pm 6.5 \mathrm{cmH}_{2} \mathrm{O}\right.$

\footnotetext{
1. Centro Universitário São Camilo, São Paulo (SP) Brasil.

2. Universidade Anhanguera, São Paulo (SP) Brasil.

3. Hospital Sírio-Libanês, São Paulo (SP) Brasil.

a. (D) http://orcid.org/0000-0002-5950-5682; b. (D) http://orcid.org/0000-0001-8934-7446; c. (DD) http://orcid.org/0000-0003-2802-893X;

d. (D) http://orcid.org/0000-0003-2515-0075; e. (D) http://orcid.org/0000-0001-6234-1458
} 

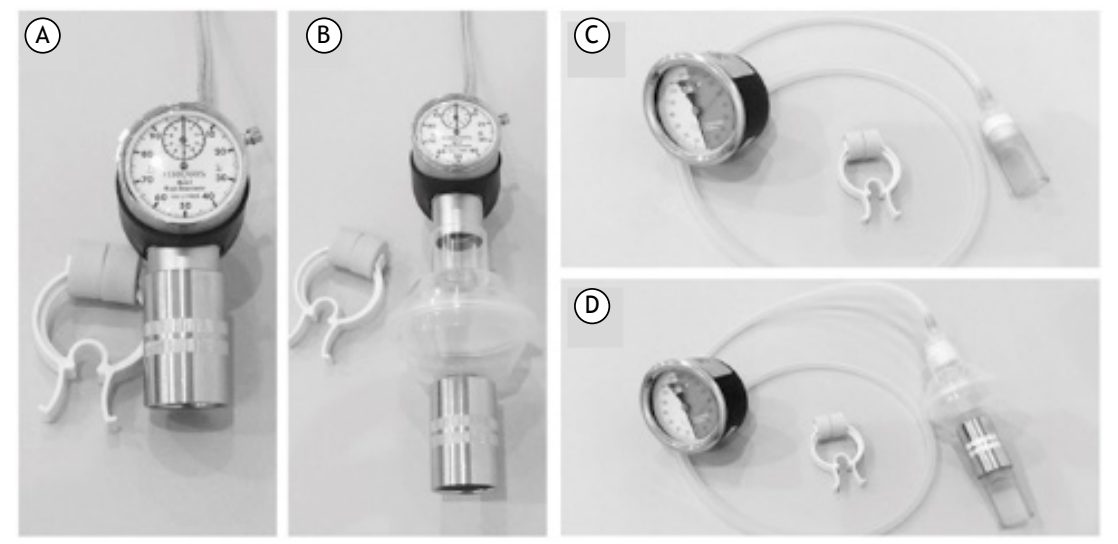

Figure 1. In $A$, a spirometer as used in the conventional method. In $B$, a spirometer equipped with a heat and moisture exchanger. In $\mathrm{C}$, a manometer as used in the conventional method. In $\mathrm{D}$, a manometer equipped with a heat and moisture exchanger.

vs. $\left.-63.8 \pm 5.5 \mathrm{cmH}_{2} \mathrm{O} ; \mathrm{p}=0.45\right)$, $\operatorname{MEP}(74.4 \pm 5.4$ $\mathrm{CmH}_{2} \mathrm{O}$ vs. $\left.73.4 \pm 6.4 \mathrm{CmH}_{2} \mathrm{O} ; \mathrm{p}=0.61\right)$, or VC $(2,338.1$ $\pm 211.5 \mathrm{ml}$ vs. $2,350.0 \pm 220.5 \mathrm{ml} ; \mathrm{p}=0.58$ ).
We conclude that the use of an HME does not modify maximal respiratory pressures and VC in patients with COPD.

\section{REFERENCES}

1. Kim NS, Seo JH, Ko MH, Park SH, Kang SW, Won YH. Respiratory Muscle Strength in Patients With Chronic Obstructive Pulmonary Disease. Ann Rehabil Med. 2017;41(4):659-666. https://doi. org/10.5535/arm.2017.41.4.659

2. American Thoracic Society/European Respiratory Society. ATS/ERS Statement on respiratory muscle testing. Am J Respir Crit Care Med. 2002;166(4):518-624. https://doi.org/10.1164/rccm.166.4.518

3. Craven ED, Steger KA, La Force FM. Pneumonia. In: Bennett JV, Brachman PS, editors. Hospital Infections. Philadelphia: LippincottRaven; 1998. p 487-511.

4. Thomachot L, Violet R, Arnaud S, Barberon B, Michael-Nguyen $A$, Martin C. Do the components of heat and moisture exchanger filters affect their humidifying efficacy and the incidence of nosocomial pneumonia? Crit Care Med. 1999;27(5):923-8. https:// doi.org/10.1097/00003246-199905000-00026

5. Lucato JJ, Nogueira da Cunha TM, Rocha SS, Palmieri de Carvalho FM, Botega DC, Torquato JA, et al. Influence of heat and moisture exchanger use on measurements performed with manovacuometer and respirometer in healthy adults. Multidiscip Respir Med. 2015;11:1. https://doi.org/10.1186/s40248-015-0037-9

6. Morgan-Hughes NJ, Mills GH, Northwood D. Air flow resistance of three heat and moisture exchanging filter designs under wet conditions: implications for patient safety. $\mathrm{Br} \mathrm{J}$ Anaesth. 2001;87(2):289-91. https://doi.org/10.1093/bja/87.2.289 